\title{
Patrimônio cultural, memória e museu: a geografia dos museus temáticos no espaço urbano de Gramado (Rio Grande do Sul, Brasil)
}

\author{
Patrimonio cultural, memoria y museo: la geografía de los museos \\ temáticos en el espacio urbano de Gramado (Rio Grande do Sul, \\ Brasil)Instructions for Authors
}

Cultural heritage, memory and museum: the geography of thematic museums in the urban space of Gramado (Rio Grande do Sul, Brazil)

Franciele Berti ${ }^{1}$

Daniel Luciano Gevehr²

\begin{abstract}
Resumo
Discute-se a relação entre a utilização do patrimônio cultural, por meio da musealização, que está ocorrendo no espaço urbano de Gramado (RS) e como este processo de difusão de museus na cidade está servindo de vetor do desenvolvimento local. Para tanto, adotou-se como técnica de coleta de dados a análise documental, explorandose o Guia dos Museus Brasileiros (2011); a Relação de Econômicos em atividade na categoria Atividades de museus e de exploração de lugares e prédios históricos e atrações similares, disponibilizada pela Prefeitura Municipal de Gramado (2016); material promocional impresso e virtual das instituições e o Guia Oficial de Localização Gramado. Percebe-se que os museus representam atrativos turísticos e, que dada a sua proliferação, o espaço urbano está constituído de uma rede de lugares que apresentam ambiências temáticas, na qual a noção de patrimônio cultural é transformada em produto turístico da cidade.
\end{abstract}

Palavras-chave: museu; patrimônio; serra gaúcha.

\section{Resumen}

Se discute la relación entre la utilización del patrimonio cultural, por medio de la musealización, que está ocurriendo en el espacio urbano de Gramado (RS) y cómo este proceso de difusión de museos en la ciudad está sirviendo de vector del desarrollo local. Para ello, se adoptó como técnica de recolección de datos el análisis documental, explorando la Guía de los Museos Brasileños (2011); La Relación de Económicos en actividad en la categoría Actividades de museos y de explotación de lugares y edificios históricos y atracciones similares, puesta a disposición por el Ayuntamiento Municipal de Gramado (2016); Material promocional impreso y virtual de las instituciones y la Guía Oficial de Localización Gramado. Se percibe que los museos representan atractivos turísticos y, dada su proliferación, el espacio urbano está constituido de una red de lugares que

\footnotetext{
${ }^{1}$ Mestranda em Desenvolvimento Regional; Faculdades Integradas de Taquara - FACCAT; Taquara, Rio Grande do Sul e Brasil; francieleberti@ hotmail.com. Trabalho apresentado no I Seminário Latino-Americano de Estudos em Cultura - SEMLACult, Foz do Iguaçu/PR, Brasil, 2017.

${ }^{2}$ Doutor em História; Faculdades Integradas de Taquara - FACCAT; Taquara, Rio Grande do Sul e Brasil; danielgevehr@hotmail.com. Trabalho apresentado no I Seminário Latino-Americano de Estudos em Cultura SEMLACult, Foz do Iguaçu/PR, Brasil, 2017.
} 
presentan ambien- temáticas, en la que la noción de patrimonio cultural se transforma en producto turístico de la ciudad.

Palabras clave: museo; Patrimonio; Sierra gaúcha.

\section{Abstract}

We discuss the relationship between the use of cultural heritage through the musealization of spaces that is occurring in the municipality of Gramado and how this process is serving as a vector for the local development. For that, the documentary analysis was adopted as a data collection technique, exploring the Guide to Brazilian Museums (2011); The Economic Relations in activity in the category Activities of museums and exploration of historical places and buildings and similar attractions, made available by Gramado City Hall (2016); Printed and virtual promotional material from the institutions listed by Gramado City Hall; The Official Gramado Localization Guide and direct observation. The results showed that although the museums analyzed represent tourism attractions and therefore generate employment and income in the municipality, excluding the economic benefits that these ventures can originate, there is no indication of direct social, cultural, environmental or educational benefits.

Keywords: museum ; patrimony; serra gaúcha.

\section{Introdução}

O turismo cultural tem sido considerado - especialmente nas últimas décadas uma alternativa para o desenvolvimento sustentável das cidades. A atividade vale-se de elementos da cultura local como atrativo turístico, contribuindo para o desenvolvimento do local e promovendo o envolvimento da comunidade (FIGUEIREDO, 2006). Assim, o patrimônio cultural está presente nos planos de desenvolvimento de áreas estagnadas, exercendo um papel de vetor para o desenvolvimento (PÉREZ, 2009).

Neste contexto de vinculação entre patrimônio, turismo e desenvolvimento, estão inseridos os museus. Estes - antes percebidos como espaços reservados à nobreza e distantes da população menos abastada - têm transcendido as classes sociais, conforme afirma Hollanda (2011). Desde a década de 1970, a função social dos museus vem sendo repensada, de forma a aproximar os lugares de memória da população das cidades.

Antes entendido como instrumento de pesquisa, de conservação, de educação, de prazer estético e intelectual, a serviço da cultura, da ciência e das artes, nas últimas décadas valoriza-se a capacidade do museu de contribuir para o desenvolvimento do espaço urbano, podendo representar um meio de administrar - de modo dinâmico - o patrimônio de uma comunidade. Além disso, no que se referem ao enfoque do desenvolvimento econômico, os museus podem funcionar como mecanismo de atração de turistas para os municípios (VARINE, 2013).

No entanto, autores como Varine (2013) e Pérez (2009) atentam para os riscos da utilização turística do patrimônio cultural, como, por exemplo, medir o patrimônio pela sua 
rentabilidade. Neste contexto, inserem-se os museus inspirados em parques temáticos. Tais empreendimentos são concebidos para fins turísticos e comerciais, em que o vínculo da instituição com a cultura local é inexistente.

Tendo esta conjuntura como ponto de partida para nossa análise, o objetivo do estudo é discutir a relação entre a utilização do patrimônio cultural por meio da musealização de espaços no espaço urbano de Gramado (RS) e como este processo está servindo de vetor do desenvolvimento local.

No desenvolvimento deste estudo adotou-se como técnica de coleta de dados a análise documental, explorando-se o Guia dos Museus Brasileiros (2011); a Relação de Econômicos em Atividade, na categoria Atividades de museus e de exploração de lugares e prédios históricos e atrações similares, disponibilizada pela Prefeitura Municipal de Gramado (2016); material promocional impresso e virtual das instituições elencadas pela Prefeitura de Gramado; o Guia Oficial de Localização Gramado e a própria observação direta.

\section{Patrimônio, turismo cultural e desenvolvimento}

Com o declínio da chamada era industrial, o século XX esteve marcado pela ascensão do setor de serviços. Neste contexto, insere-se a participação do turismo, ramo da economia que mais cresce e é considerada atualmente uma das principais atividades econômicas mundiais (DIAS, 2013).

Iniciamos a discussão com as ideias apresentadas por Margarita Barreto (2015) que argumenta que existem diversas definições sobre turismo. Para a autora, a variedade conceitual é oriunda da complexidade que permeia o fenômeno, bem como devido à interpretação de cada pesquisador - inerente a sua formação acadêmica - devido às diversas áreas do conhecimento que se debruçam acerca do tema, este está sujeito a algumas divergências. Barreto $(2015$, p.09) afirma ainda que "[...] basta dizer simplesmente que o turismo é um fenômeno social que atualmente abrange o mundo inteiro, do ponto de vista geográfico, e todos os grupos e camadas sociais”.

Neste contexto é que se insere um elemento relativamente recente, o turismo cultural como parte das novas atividades urbanas. O turismo e a cultura apresentam vínculos estreitos, uma vez que a atividade turística tem sua natureza fundamentada na cultura, pois representa um "processo de interações contínuas" entre pessoas que ocupam espaços diferentes, e é 
precisamente essa diversidade que atrai o turista (DIAS, 2006). Para o Ministério do Turismo (2006, p. 13) "Turismo Cultural compreende as atividades turísticas relacionadas à vivência do conjunto de elementos significativos do patrimônio histórico e cultural e dos eventos culturais, valorizando e promovendo os bens materiais e imateriais da cultura".

Ainda de acordo com Varine (2013) essa tipologia de turismo é motivada, especialmente, pelo interesse de turistas em descobrir lugares, paisagens, sociedades e patrimônios locais. O turismo cultural assume, cada vez mais, um papel educativo, responsável por propagar e solidificar um conhecimento advindo de um processo complexo (DIAS, 2006).

O turismo cultural tem sido considerado uma alternativa para o desenvolvimento sustentável de cidades e diferentes regiões do Brasil. A atividade vale-se de elementos da cultura local como atrativo turístico, contribuindo para o desenvolvimento do local e promovendo o envolvimento da comunidade (FIGUEIREDO, 2005). A expressão "desenvolvimento", sendo distinguida de "crescimento", traz consigo a perspectiva material e imaterial, integrando diferentes dimensões - econômica, social, cultural, ambiental, política... - promovendo a dinamização econômica, tendo em vista, fundamentalmente, a melhoria da qualidade de vida população (DALLABRIDA, 2007).

Varine (2013) pondera sobre a dicotomia existente acerca de desenvolvimento. Para o autor, ainda que a ideia desenvolvimento local e desenvolvimento sustentável não seja nova, a maneira como são concebidos e conduzidos ocorre, geralmente, é equivocada. O autor menciona que os especialistas do desenvolvimento - tais como políticos, universitários, jornalistas, economistas, entre outros - comumente associam "desenvolvimento local" com "desenvolvimento econômico local"; neste sentido, as ações são delineadas com vistas à perspectiva econômica.

Por outro lado, menciona o autor, agentes do patrimônio - arquitetos, conservadores, agentes culturais ou turísticos, historiadores, arqueólogos e outros - almejam um desenvolvimento cultural, tradicionalmente vinculados à conservação, restauração, inventários, etc. Assim, a relação entre o patrimônio e o desenvolvimento local assume perante os profissionais envolvidos - uma lógica dicotômica, sem haver reflexão e interação entre os universos.

O mesmo autor sugere que deve haver reflexão e interação entre ambas as linhas de raciocínio - econômica e cultural - uma vez que o patrimônio material ou imaterial, "vivo ou morto" é combustível para o desenvolvimento. O desenvolvimento é sustentável se ocorrer, 
de forma harmoniosa, com o patrimônio. Logo, um território que ignora os patrimônios materiais e imateriais não poderá ser base para um desenvolvimento local sustentável.

Assim sendo, o transcorrer do turismo cultural deve estar respaldado na valorização e promoção da cultura local e regional, dos bens materiais e imateriais, preservação do patrimônio histórico e cultural, geração de empregos no setor (MINISTÉRIO DO TURISMO, 2006). No Brasil, a atividade turística cultural esteve restrita ao patrimônio edificado e festas tradicionais, no entanto, observa-se que nos últimos anos o leque de produtos turísticos e culturais do país vem aumentando (MINISTERIO DO TURISMO, 2006).

Vale destacar que o desenvolvimento local ou regional representa uma alternativa mais viável para enfrentar a globalização. A globalização reforça o local, dado que estimula a organização da comunidade com vistas ao local se viabilizar economicamente (CAMPANHOLA; SILVA, 2001). É preciso lembrar, ainda, que o patrimônio cultural está presente nos planos de desenvolvimento em áreas estagnadas, exercendo um papel de vetor para o desenvolvimento (PÉREZ, 2009). Conforme sustenta Varine (2013) o patrimônio está presente em todos os lugares e, portanto, cabe a cada localidade, descobrir e explorar - de forma equilibrada - suas potencialidades.

\section{Museus, turismo e espetacularização}

$\mathrm{Na}$ perspectiva de estabelecer possíveis vinculações entre patrimônio, turismo e desenvolvimento, é que situamos os museus. Os museus - antes percebidos como espaços reservados à nobreza e distantes dos menos abastados - têm transcendido as classes sociais. Conforme Hollanda (2011, p. 09) os museus cada vez mais “[...] se fortalecem como espaços mais próximos da população, que não precisam apenas existir para serem públicos, precisam também interagir; não só abrir portas, mas também abrir caminhos [...]”.

Para melhor compreendermos o objeto da pesquisa, cabe lembrar que a primeira definição de museu foi desenvolvida pelo International Council of Museums (ICOM), em 1946, sendo reformulada nos anos de 1956, 1974, 1989, 1995 e 2001 (PÉREZ, 2009). A definição usual de museu obedece essencialmente à proposição do ICOM, elaborada em 1974 (POULOT, 2013) e que define o museu como uma instituição: [...] sem fins lucrativos, a serviço da sociedade e de seu desenvolvimento, aberta ao público [...] tendo em vista a aquisição, conservação, transmissão e, principalmente, exposição desse acervo com a finalidade de estudo, educação e deleite. 
Discutindo sobre as alterações ocorridas no conceito, Pérez (2009) atenta para a convergência nas definições estabelecida pelo órgão. Para o autor, a concepção fundamental é de que o museu é mais do que uma coleção de objetos, é uma instituição permanente a serviço da comunidade.

O museu, antes entendido como instrumento de pesquisa, de conservação, de educação, de prazer estético e intelectual, a serviço da cultura, da ciência e das artes, a partir da década de 1970 passa a ser um instrumento a serviço do desenvolvimento, podendo representar um meio de administrar de modo dinâmico o patrimônio de uma comunidade. Além disso, no que se refere ao enfoque de desenvolvimento econômico, os museus podem funcionar como mecanismo de atração de turistas (VARINE, 2013).

Perez (2009) corrobora com tal afirmação ao mencionar que, ainda que o fundamento das instituições museais consista no patrimônio cultural e natural, atualmente estas têm despontado, enquanto um instrumento fundamental para o desenvolvimento local, por meio de sua exploração turística. Elas transcendem a função de meio de veiculação de ideias, valores, identidade, apresentando-se como um "espaço a serviços das comunidades". É indubitável a relevância dos museus para a atividade turística e, assim, os especialistas em turismo devem valer-se dos diferentes tipos de museus, objetivando o desenvolvimento sustentável (PÉREZ, 2009).

Entretanto, Varine (2013) sublinha a visão economicista que comumente tem cercado o turismo cultural. Para o autor, direcionando o turismo apenas como fonte de receitas, os responsáveis locais - tanto pelo turismo, quanto pelo desenvolvimento - não se percebem a relevância do turismo cultural para a imagem do território e, por conseguinte, para as estratégias de desenvolvimento. O mesmo autor questiona a faceta verdadeiramente cultural do fenômeno. Assim, é preciso questionar sobre o real impacto desse tipo de turismo na população e na cidade.

Neste sentido, pode-se citar o economuseu, conceito concebido no Canadá há mais de trinta anos. A economuseologia está embasada na filosofia de "desenvolvimento durável" defendida e propagada pela Organização das Nações Unidas para a Educação, a Ciência e a Cultura (UNESCO) (TINOCO, 2009). Também intitulados de "museus-empresas", os economuseus associam economia e museologia e seu funcionamento dar-se-á por meio de roteiros turísticos, em que o visitante observa a produção do artesanato - fundamentalmente vinculado à cultura local - e, em seguida, as peças são exposta e postas à venda (NASCIMENTO 2010). 
O conceito de ecomuseu ou Museu-Empresa foi criado por Cyrill Simard e dentre as possíveis vantagens dessa tipologia de museu, Tavares (2003) elenca a promoção da identidade cultural local, aumento de renda, valorização do trabalho do artesão engrandece a autoestima, bem como a identidade local e o senso de pertencimento e, por conseguinte, estímulo à permanência da população em seu local de origem.

Varine (2013) atenta para um possível discurso que procura dissimular as reais intenções dessas instituições. Essa tipologia de museu é uma "fórmula turística" com fins essencialmente lucrativos, dada a exploração fundamentalmente econômica e comercial do patrimônio, sem qualquer vínculo com aspectos culturais da comunidade de pertencimento. Diante da sociedade de consumo, os economuseus são distorções do uso do patrimônio, em que o discurso cultural é um mecanismo para mascarar finalidades exclusivamente comerciais.

A cultura do consumo tem-se difundido pelo mundo. A busca constante pelo lucro tem levado museus a sucumbirem a novas condições, condições estas que atacam perigosamente a ética dos museus, como a redução do patrimônio à mercadoria e à competição com indústrias de espetáculo. Desde a segunda metade do século XX, o modelo de gestão tradicional de museus enfrenta crise. De um lado, a gestão economicista, que entende o museu como negócio, de outro lado, um modelo de gestão até então intocado, que vê o museu enquanto uma ferramenta para a formação, conservação, memória e história (MOLFINO, 2015).

A concepção de museu espetacularizado tem sido alvo de críticas, tendo em vista sua função limitada de lazer e atrair público [enquanto produto turístico]. No entanto, na disputa entre museu-empresa e museu, enquanto espaço de memória, quem parece perder são os defensores da visão mais conversadora (MOLFINO, 2015). Isso ocorre, na medida em que a nova dinâmica de produção dos espaços urbanos acaba inserindo o museu no cenário contemporâneo, no qual o museu enquanto espetáculo se transforma numa mercadoria voltada para o consumo de massa.

\section{A cidade e a espetacularização dos museus}

O município de Gramado localiza-se no Rio Grande do Sul, a 885 metros de altitude, na encosta inferior do nordeste. O clima no município é subtropical úmido e apresenta em sua paisagem as florestas de Araucária, atualmente considerada patrimônio natural do município. 
Com uma população de 32.273 habitantes (IBGE, 2010), em uma área de 237,827 km² (IBGE, 2015), Gramado é referência no setor turístico em âmbito nacional e conhecida especialmente como a cidade do Festival de Cinema de Gramado. O potencial turístico da localidade é cada vez mais explorado e configura-se como imagem de destino consolidado (MINISTÉRIO DO TURISMO, 2015). O município está localizado na denominada "Região das Hortênsias" [tal regionalização abrange também Canela, Nova Petrópolis e São Francisco de Paula].

Dentre os atrativos turísticos de Gramado, destacam-se os museus. Essa tipologia de instituição tem se proliferado nos últimos anos, não somente no município, mas também no país e no mundo. Devido à ampliação da acessibilidade da cultura, essa tipologia de instituição se difunde no país, inovando e desenvolvendo constantemente seu repertório (HOLLANDA, 2011).

Visando identificar os museus estabelecidos em Gramado, consultamos inicialmente o Cadastro Nacional Museu (CNM), criado pelo Instituto Brasileiro de Museus (IBRAM/Minc) em 2006, cujo objetivo é mapear e cadastrar os museus do Brasil. De acordo com o órgão, a referida ferramenta foi concebida visando a integrar informações acerca do setor museal, orientando e fomentando a realização de ações nesta área, por meio de coleta, registro e disseminação de informações. Assim, pretendeu-se compartilhar as informações com a sociedade, configurando-se como fonte de pesquisa e difusor dos museus brasileiros, estimulando a visitação.

Desde a sua concepção, o CNM já mapeou mais de 3.200 instituições museológicas em todo o país, compartilhando seus resultados por meio de duas publicações, dentre elas o Guia dos Museus Brasileiros, lançado em 2011. O instrumento reúne informações sobre o ano de criação, situação atual, endereço, tipologia de acervo, acessibilidade, infraestrutura para o recebimento de turistas estrangeiros, horário de funcionamento e natureza administrativa de todos os museus já mapeados pelo IBRAM em território nacional. O Guia compreende 3.118 museus, incluindo 23 museus virtuais, já mapeados pelo IBRAM em território nacional.

Inicialmente, a coleta de dados foi realizada, fundamentada no conceito formulado pelo então Departamento de Museus e Centros Culturais do Instituto do Patrimônio Histórico e Artístico Nacional, que estabelecia que o museu

[...] é uma instituição com personalidade jurídica própria ou vinculada a outra instituição com personalidade jurídica, aberta ao público, a serviço da sociedade e de seu desenvolvimento [...] e está [...] a serviço da sociedade com o objetivo de propiciar à ampliação do campo de possibilidades de construção identitária, à 
percepção crítica da realidade, a produção de conhecimentos e oportunidades de lazer; (GUIA DOS MUSEUS BRASILEIROS, 2011, p. 14).

Sendo assim, segundo o IBRAM, foram considerados museus, independentemente de sua denominação, as "instituições ou processos museológicos que apresentem as características acima indicadas e cumpram as referidas funções museológicas". Em 2009 o CNM passou a adotar o conceito de museu estabelecido pelo Estatuto de Museus, promulgado pela Lei $n^{\circ} 11.904$, de 14 de janeiro de 2009, que institui:

Consideram-se museus, para os efeitos desta Lei, as instituições sem fins lucrativos que conservam, investigam, comunicam, interpretam e expõem, para fins de preservação, estudo, pesquisa, educação, contemplação e turismo, conjuntos e coleções de valor histórico, artístico, científico, técnico ou de qualquer outra natureza cultural, abertas ao público, a serviço da sociedade e de seu desenvolvimento.

Parágrafo único. Enquadrar-se-ão nesta Lei as instituições e os processos museológicos voltados para o trabalho com o patrimônio cultural e o território visando ao desenvolvimento cultural e socioeconômico e à participação das comunidades.

(GUIA DOS MUSEUS BRASILEIROS, 2011, p. 15).

No que se refere ao município de Gramado, o Guia apresenta oito museus e a respectiva tipologia de acervo, natureza administrativa e ano de criação, conforme mostra o Quadro 1.

\begin{tabular}{|l|l|l|l|}
\hline Nome do museu & Tipologia de acervo & $\begin{array}{l}\text { Natureza } \\
\text { administrativa }\end{array}$ & Ano de criação \\
\hline $\begin{array}{l}\text { Museu do Perfume } \\
\text { Fragram }\end{array}$ & $\begin{array}{l}\text { Ciências Naturais e } \\
\text { História Natural; }\end{array}$ & Privado & 1993 \\
\hline $\begin{array}{l}\text { Museu Medieval } \\
\text { Castelo Saint George }\end{array}$ & $\begin{array}{l}\text { Antropologia e } \\
\text { Etnografia; } \\
\text { Visuais; História }\end{array}$ & Particular & 1999 \\
\hline $\begin{array}{l}\text { Museu do Festival de } \\
\text { Cinema }\end{array}$ & $\begin{array}{l}\text { Artes Visuais; História; } \\
\text { Imagem e Som }\end{array}$ & Público-municipal & 2000 \\
\hline $\begin{array}{l}\text { Museu de Artes Dr. } \\
\text { Carlos Nelz }\end{array}$ & Artes Visuais & $\begin{array}{l}\text { Informação não } \\
\text { disponível }\end{array}$ & 1992 \\
\hline $\begin{array}{l}\text { Museu Histórico } \\
\text { Municipal; }\end{array}$ & $\begin{array}{l}\text { Artes Visuais; Ciência } \\
\text { e Tecnologia; História. }\end{array}$ & Público-municipal & 1982 \\
\hline Prof. Hugo Daros & $\begin{array}{l}\text { Informação não } \\
\text { disponível }\end{array}$ & $\begin{array}{l}\text { Informação não } \\
\text { disponível }\end{array}$ & 1993 \\
\hline Museu do Sapato & Privado-empresa & 2001 \\
\hline
\end{tabular}


RELACult - Revista Latino-Americana de Estudos em Cultura e Sociedade

\begin{tabular}{|l|l|l|l|}
\hline & disponível & & \\
\hline Museu do Piano & $\begin{array}{l}\text { Informação não } \\
\text { disponível }\end{array}$ & Privado-empresa & 1999 \\
\hline
\end{tabular}

Quadro 1 - Museus cadastrados no Guia dos Museus Brasileiros em 2011

Fonte: Adaptado de Guia dos Museus Brasileiros (2011)

Já no Quadro 2, apresentado abaixo, a Prefeitura Municipal de Gramado (2016) também registra oito empreendimentos vinculados ao segmento denominado "Atividade de museu e exploração de lugares e prédios históricos e atrações similares", pela Classificação Nacional de Atividades Econômicas (CNAE), sendo eles:

\begin{tabular}{|l|l|l|l|}
\hline Nome do museu & Tema & $\begin{array}{l}\text { Natureza } \\
\text { administrativa }\end{array}$ & Ano de criação \\
\hline Hollywood Dream Cars & Carros antigos & Privado & 1997 \\
\hline $\begin{array}{l}\text { Museu de Cera de Gramado } \\
\text { Dream Land }\end{array}$ & Personagens em cera & Privado & 2009 \\
\hline $\begin{array}{l}\text { Museu Medieval Castelo Saint } \\
\text { George }\end{array}$ & Cutelaria medieval & Privado & 2002 \\
\hline $\begin{array}{l}\text { Museu Gramado Minerais e } \\
\text { Pedras Preciosas }\end{array}$ & Pedras preciosas & Privado & 2010 \\
\hline Super Carros Gramado & Carros esportivos & Privado & 2011 \\
\hline Museu do Festival de Cinema & Cinema & Público-privado & 2016 \\
\hline A mina & $\begin{array}{l}\text { Potocicletas Harley } \\
\text { Davdson }\end{array}$ & Privado & 2012 \\
\hline
\end{tabular}

Quadro 2 - Museus Cadastrados na Prefeitura Municipal de Gramado no ano de 2016

Fonte: elaborado pelos autores (2017).

Comparando os dados expressos nos Quadros 1 e 2, percebemos que o Guia dos Museus Brasileiros e a Prefeitura Municipal de Gramado registram oito museus, no entanto, divergem quanto às instituições cadastradas. Tal desconformidade pode estar relacionada, em parte, devido à diferença do período entre o mapeamento (2011-2016). Não obstante, a principal causa remete aos diversos critérios estabelecidos para a triagem. O Museu do 
Perfume Fragram, por exemplo, não consta na listagem do Quadro 2, tendo em vista que, segundo a Prefeitura Municipal de Gramado, o estabelecimento está registrado com CNAE de Indústria e Comércio de Perfumes e não como museu.

Neste sentido, no que se refere às indefinições e discrepâncias quanto ao número de museus, que varia de acordo com a fonte pesquisada, Poulot (2013) menciona que o número atual de museus é indeterminado, uma vez que a seleção depende da escolha dos critérios. Para o autor, a situação se agrava à medida que se expandem constantemente as definições, suscitando mais incertezas estatísticas.

Entendemos que os museus mapeados pelo IBRAM estão conectados às histórias e as memórias da comunidade gramadense ou, ao menos, manifestam, expõem, investigam ou interpretam bens culturais associados à cultura local. Já as instituições cadastradas na Prefeitura Municipal de Gramado parecem ter, sobretudo, vocação comercial, uma vez que não há vínculo qualquer com a cultura da comunidade.

A seguir, descrevemos os museus mapeados pela Prefeitura de Gramado e que se encontram situados em áreas de destaque do espaço urbano [e de forte especulação imobiliária], constituindo-se praticamente todos em uma única "rota de museus". Essa rota está localizada na Avenida das Hortênsias, que liga Gramado à Canela e onde estão situados diversos restaurantes e casas comerciais, voltadas para os turistas que visitam a cidade.

O fato de localizaram-se - quase que em sua totalidade - numa área valorizada da cidade coloca os museus em evidência, na medida em que esses lugares acabam tendo sua visibilidade garantida em razão da sua posição estratégica no contexto urbano de Gramado.

O primeiro caso estudado é o Museu do Festival de Cinema, que busca difundir a história e a evolução do Festival de Cinema de Gramado, cuja primeira edição ocorreu em janeiro de 1973, inserida na programação da extinta Festa das Hortênsias. O empreendimento foi desenvolvido no ano 2000 e reconfigurado em 2016 e localiza-se na área central da cidade, podendo ser considerado o "coração da cidade" e ponto de referência para quem circula pelo espaço urbano de Gramado.

Dentre as alterações, pode-se destacar a mudança da sede [atualmente o Museu está instalado junto ao Palácio dos Festivais, ponto turístico localizado na Avenida Borges de Medeiros e que é sede de exibição dos filmes participantes do Festival de Cinema de Gramado], a natureza administrativa [fruto da nova parceria público-privada], a instalação de um espaço de café e a incorporação de recursos digitais, que permitem a interatividade.

O empreendimento é inspirado no Museu da Língua Portuguesa, localizado na Praça da Luz, em São Paulo. A inspiração se dá, essencialmente, pelos recursos de interatividade e 
tecnologia utilizados para apresentar a história do evento. Neste sentido, há uma combinação de acervos históricos e tecnologia, de maneira que o visitante possa interagir buscando o material histórico em totens eletrônicos. Além de acervo virtual e ferramenta de pesquisa, os totens disponibilizam jogos da memória e um 'quiz', ambos fundamentados no Festival de Cinema de Gramado. O museu possibilita, ainda, a gravação de um pequeno filme pelo visitante. Tal interação entre museu e visitante se dá com o intuito de estreitar a relação entre ambos e estimular a criatividade do participante.

Nos últimos anos os museus têm assumido uma nova roupagem, modificando sua maneira de apresentação. Antes os museus eram percebidos como locais de armazenamento de objetos em desuso; as visitas eram tradicionalmente austeras e requeriam uma postura "compenetrada e sisuda", atualmente, visando a atratividade dos visitantes e da comunidade, estão sendo inseridas novas atividades, como aulas de pinturas, decoração, exposição de obras de artes de artistas da própria localidade (PIRES, 2001).

As novas tecnologias, concebidas e difundidas com rapidez, obrigaram os museus a repensar as técnicas de comunicação audiovisual e apresentação. Estes, cada vez mais valemse da tecnologia - entendo-as como aliadas e não como concorrentes - lançando mão de equipamentos lúdicos para permitir a interação entre o museu e o visitante (BARRETO, 2000). Os museus - compreendidos como parte da urbe contemporânea - têm promovido uma mutação na apresentação de acervos, incorporando técnicas dinâmicas e interativas que geram movimento, som e cheiro (MINISTÉRIO DO TURISMO, 2006).

Nesta mesma linha, insere-se o Museu Super Carros, que concentra um acervo de carros superesportivos. Dentre as atrações do empreendimento, destacam-se os simuladores de Fórmula 1, com movimento e estáticos; cinema 9D; fotos personalizadas dentro dos carros e duas lojas de produtos.

Outro museu instalado em Gramado é o Museu Medieval Castelo Saint George. O museu possui um acervo de cutelaria medieval, exposto em vitrines. Há réplicas de armas dos filmes, espadas de Samurais, facas, lanças, entre outros. A arquitetura é inspirada nas fortalezas medievais, construído com pedras de arenitos, portas e janelas de madeira itaúba maciços, confeccionados pelo proprietário. Esse museu nos faz pensar naquilo que Arantes (1991) chama de estetização em primeiro lugar, na medida em que a autora defende que os novos museus priorizam a arquitetura estética em detrimento do acervo, fazendo com que a arquitetura se apresente como "um valor em si mesmo" e que procura chamar a atenção no contexto urbano contemporâneo. 
Já o Museu Gramado Minerais e Pedras Preciosas tem um acervo com aproximadamente 500 pedras semipreciosas, como ametistas, ágatas e opalas, provenientes de diversas partes do mundo. Nesse mesmo gênero, A Mina apresenta mais de 1000 exemplares de pedras preciosas do Brasil e de outros países como a África do Sul, Argentina, Austrália, China, Congo, Índia, entre outros. Os museus temáticos Holywood Dream Cars, Dream Land, Harley Motor Show - e o já descrito Super Carros - têm apelo lúdico como principal característica, estando essas características já expostas na parte externa dos museus e chamam a atenção no contexto urbano no qual estão inseridos. Os quatro empreendimentos são integrantes dos oito comandados pelo grupo Dreams. O Holywood Dream Cars, o mais antigo do quarteto, é uma exposição de carros antigos. A exibição remete ao "glamour" de Hollywood nas décadas de 1950 e 1960. Também o Museu de Cera Dream Land apresenta mais de 50 astros do cinema e personalidades distribuídos em dezoito cenários temáticos.

Localizado no subsolo do Museu de Cera Dream Land, o Harley Motor Show se apresenta como o único empreendimento temático da América do Sul a homenagear a marca de motocicletas. Em uma área de aproximadamente 1000 metros quadrados, o local expõe mais de vinte motos. No local, é possível perceber que no ambiente interno há o predomínio e a vivacidade de cores no design. Assim como o Museu do Festival de Cinema, o Harley Motor Show também dispõe de equipamentos de oferta alimentar e um bar de funcionamento noturno, o que atraia um número maior de pessoas e coloca o espaço no roteiro de diversão da cidade.

Com exceção do Museu do Festival de Cinema, que se dedica à memória do Festival de Cinema, evento vinculado diretamente à comunidade de Gramado, os museus de Gramado estão limitados à exploração econômica e comercial, sem vínculo com a cultura e representação da comunidade. Afinal, eles não apresentam aspectos da cultura local, ao mesmo tempo em que importam elementos vindos de fora e que não estabelecem nenhuma relação com a paisagem e a sociedade local [influenciada pela presença dos imigrantes alemães, italianos e portugueses, que colonizaram o município no século XIX].

Se por um lado existe uma preocupação, por parte dos moradores e da própria municipalidade em se preservar a cultura trazida pelos imigrantes que colonizaram a região [perceptível através da arquitetura, da culinária e das festas típicas] os museus se situam na contramão desse processo. Explorando elementos da cultura internacional - e marcadamente globalizada - os museus contribuem para a valorização da cultura que não é produzida no próprio local, ou seja, importa elementos de fora para dentro da cidade.

Os museus [de forte apelo turístico] de Gramado podem ser descritos como "museus parque temáticos", apresentando características análogas ao já citado anteriormente 
economuseu, no entanto, inspirados nos parques temáticos de tipo Disneylândia, configurando-se como "armadilhas para turistas" (VARINE, 2013) dispostas pelo espaço urbano de Gramado. Diante dessa banalização, o patrimônio cultural se resume a um bem comercial como qualquer outro, a cultura e patrimônio perdem suas funções sociais educadoras e educativas (PEREZ, 2009).

Nesta tipologia de museu, a relação comunitária, territorial ou cultural é pouco expressiva ou inexistente e o encadeamento com o desenvolvimento global é "fraca ou duvidosa". O empreendimento poderia ser implantado em qualquer lugar, uma vez que a distância entre a cultura e o local é evidente (VARINE, 2013).

Tomando como referência as informações [através de uma conversa informal] de um profissional do Centro de Atendimento ao Turista, durante os procedimentos para coleta de dados, pode-se perceber mais claramente que o entendimento [dos gestores municipais e profissionais atuantes na área do turismo] acerca da concepção de museu é ambíguo e confunde-se com parque temático.

De acordo com o funcionário, a concentração de museus está entre os itens 27 e 34 do Guia Oficial de Localização de Gramado, na qual estão inclusos os parques temáticos Mini Mundo, Mundo de Chocolate e o Reino do Chocolate que são, na prática, parques temáticos e não museus, como menciona o representante do setor de turismo da cidade. Nessa mesma linha de raciocínio, também é possível destacar um outdoor instalado em uma das principais vias de acesso a Gramado. O anúncio faz menção à compra de ingressos para os parques temáticos do município, no entanto, a ilustração inclui imagens do Museu de Cera Dream Land, Harley Motor Show, Holywood Dreams Cars e Super Carros.

A análise ao Guia permitiu perceber, também, que não há alusão aos museus que estão vinculados à história local - que Poulot (2013) considera "museus de verdade" - como o Museu de Artes Dr. Carlos Nelz e o Museu Histórico Professor Hugo Daros. Neste sentido, vale atentar para o projeto do Museu Major José Nicoletti Filho que tem como objetivo apresentar a história do primeiro superintendente de Gramado, bem como peças e cenários dos diferentes momentos história do município e de seus habitantes (NANDI, VIDAL e GEVEHR, 2015). O museu poderá promover a valorização da história e da cultura local. No entanto, o projeto tem evoluído vagarosamente desde o ano de 2009.

Os museus de Gramado têm se convertido, cada vez mais, em atrativos turísticos rentáveis. Autores como Huyssen (1997), Pérez (2009), Poulot (2013) assinalam a proliferação dessas instituições. Huyssen (1997), por sua vez, chama este fenômeno de "museumania". No entanto, se por um lado há uma multiplicação de museus voltados ao 
consumo turístico, por outro, vão desaparecendo instituições museais que não se submetem aos processos de espetacularização (PÉREZ, 2009).

Os museus analisados incorporam estratégias de marketing, buscando a identificação e, por conseguinte, a satisfação das necessidades humanas e sociais (KOTLER; KELLER, 2006). Dois dos empreendimentos dispõem de equipamentos de oferta alimentar, além disso, o roteiro das visitas aos museus encerram nas lojas de souvenirs, pertencentes aos estabelecimentos, tal intervenção de roteiro é empregada nos oito empreendimentos pesquisados. Chama atenção, também, a localização geográfica das referidas instituições, que se colocam como "vitrines" no espaço urbano de Gramado - dada a sua configuração arquitetônica e a utilização de recursos de marketing para atrair os turistas que percorrem as ruas e avenidas da cidade.

Dentre os 08 museus, 06 estão localizados na Avenida das Hortênsias. A referida avenida cruza o município de Gramado no sentido leste-oeste e conecta-se ao município de Canela [localizado a $7 \mathrm{~km}$ de Gramado, também pertencente a "Região das Hortênsias" e com economia firmada na atividade turística] e assim, constitui-se de uma área de intensa circulação turística. Essa geografia dos museus de Gramado nos permite avaliar como a criação dos museus acabou interferindo na dinâmica de produção do espaço urbano, na medida em que colocou em relevou áreas de forte apelo turístico da cidade, contribuindo assim para a valorização dessas áreas e a própria especulação imobiliária nas áreas próximas aos estabelecimentos.

Já o Museu do Festival de Cinema [mencionado anteriormente] localiza-se na Avenida Borges de Medeiros, considerada cartão postal do município, voltada para o segmento comercial, concentrando estabelecimentos direcionados fundamentalmente ao turista. O Museu A Mina, embora não instalado em áreas de circulação turística, está inserido em um parque com atrações turísticas já consolidadas. Pensando nessa questão, tomamos as ideias de Molfino (2015), que afirma que a partir da década de 1990 os museus aderiram às técnicas utilizadas nas organizações empresariais e comerciais, tais como a autonomia de gestão, intensificação dos pontos fortes, indicadores de resultados, comunicação e marketing.

\section{Considerações finais}

Discutiu-se a relação existente entre a utilização do patrimônio cultural, por meio da musealização de espaços, que está ocorrendo em Gramado e como este processo está servindo de vetor do desenvolvimento local. Para tanto, adotou-se como técnica de coleta de dados a 
análise documental, explorando-se o Guia dos Museus Brasileiros (2011); a Relação de Econômicos, em atividade na categoria Atividades de Museus e de exploração de lugares e prédios históricos e atrações similares, disponibilizada pela Prefeitura Municipal de Gramado (2016); material promocional impresso e virtual das instituições elencadas pela Prefeitura de Gramado; o Guia Oficial de Localização Gramado e a observação direta dos lugares selecionados no recorte espacial da pesquisa.

Percebe-se que os museus têm passado por profundas transformações e apresentado novas perspectivas de diálogo com o espaço urbano nos quais está inserido. Visando atrair visitantes [ou seriam consumidores] as instituições abandonam cada vez mais a visita percebida tradicionalmente como introvertida e conservadora, de contemplação e concentração, configurando-se atualmente como instituições que apresentam seus acervos de maneira dinâmica e interativa. Os museus encontraram na atividade turística uma fonte de sustento, transformando não apenas a ideia de patrimônio cultural mas também a própria paisagem urbana, que passa a contar com uma nova arquitetura, voltada para o espetáculo e para a valorização de novos elementos, até então estranhos à própria comunidade.

A reformulação dos museus na sociedade capitalista parece exceder-se na exibição e encenação, valendo-se progressivamente de cenários cinematográficos e reproduzindo imagens percebidas em parques temáticos, tal panorama parece ilustrar um "alinhamento progressivo da instituição à vulgaridade comercial” (POULOT, 2013, p. 106).

Esta conjuntura foi observada nos museus estabelecidos em Gramado, dado que o turismo no município tem atribuído novas funções aos museus e estes têm concorrido cada vez mais com indústrias de lazer, tais como os parques temáticos existentes do local. A análise revelou que os museus tem-se apresentado como atrações turísticas rentáveis economicamente. Assim, Gramado tem experimentado uma proliferação de museus na última década. Atualmente o município registra oito empreendimentos no ramo, e não obstante apenas um apresenta algum vínculo com a cultura local.

Os museus [e sua dinâmica de relação com a produção do espaço urbano] devem ser pensados como instituições que contribuem para o desenvolvimento local, tendo em vista que na concepção de desenvolvimento seja fundamental a melhoria da qualidade de vida da população, seja em aspectos econômicos, sociais, culturais ou ambientais. Excetuando o Museu do Festival de Cinema que mesmo após ser reconfigurado [aderindo a recursos audiovisuais] mantém intenções didáticas, contribuindo para a preservação da memória do Festival de Cinema de Gramado, evento vinculado à comunidade de Gramado. Percebe-se que no caso dos demais museus, os mesmos estão limitados à exploração econômica e 
comercial, voltados para o consumo de massa, desprovidos de vínculo com a cultura e representação da comunidade.

A análise permitiu inferir, também, que não há uma concepção sólida acerca do conceito de museu. A indefinição foi percebida no mapeamento das instituições, que variam de acordo com a fonte pesquisada. Neste sentido, outro fato observado é que a concepção de museu é ambígua. Perante as produções e encenações praticadas pelas instituições, museus são entendidos e vendidos, também, como parques temáticos.

Por fim, cabe lembrar que, ainda que os museus representem atrativos turísticos e, por conseguinte, geram emprego e renda no município [tendo em vista o efeito multiplicador e difusor da atividade turística], a reprodução desse modelo cultural acaba contribuindo para a transformação profunda da paisagem cultural da cidade, na medida em que esses novos espaços [museus e parques] produzem cenas inusitadas em Gramado

\section{Referências}

ARANTES, Otilia. Os novos museus. Novos Estudos CEBRAP, v. 31, p. 161-169, 1991. (Artigo em Periódico Digital)

BARRETO, Margarita. Cultura e Turismo: Discussões contemporâneas. Campinas: Papirus, 2015. (Obra Completa)

BARRETTO, Margarita. Turismo e legado cultural: as possibilidades do planejamento. Campinas: Papirus, 2000. (Obra Completa)

BENI, Mario. Turismo: Planejamento estratégico e capacidade de gestão - Desenvolvimento Regional, Redes de Produção e Clusters.Barueri: Manole, 2012. (Obra Completa)

BRASIL. Instituto Brasileiro de Museus. Guia de Museus Brasileiros. Brasília, 2011. Disponível em: < http://www.museus.gov.br/wp-content/uploads/2011/05/gmb_sul.pdf > . Acesso em: 28 nov. 2016.

BRASIL. Ministério do Turismo. Gramado (RS) aposta na expansão do turismo de negócios. 2015. Disponível em: < http://www.turismo.gov.br/\%C3\%BAltimasnot\%C3\%ADcias/5109-gramado-(rs)-aposta-na-expansao-do-turismo-denegocios.html>.Acesso em: 12 set. 2016.

BRASIL. Ministério do Turismo. Segmentação do Turismo: Marcos Conceituais. Brasília: Ministério do Turismo, 2006.

CAMPANHOLA, Clayton; GRAZIANO DA SILVA, José. Agroturismo como nova fonte de renda para o pequeno agricultor brasileiro. In: ALMEIDA, Joaquim Anecio; RIEDL, Mário.Turismo Rural: Ecologia, Lazer e Desenvolvimento. Bauru: Edusc, 2001. p. 146-179. (Capítulo de Livro). 
DALLABRIDA, Valdir Roque. A gestão territorial através do diálogo e da participação. Scripta Nova: revista electrónica de geografía y ciencias sociales, n. 11, p. 19, 2007. (Artigo em Periódico Digital)

DIAS, Reinaldo. Turismo e Patrimônio Cultural: Recursos que acompanham o crescimento das cidades. São Paulo: Saraiva, 2006. (Obra Completa)

DREAM LAND (Gramado). Informaçoes. Disponível em:

<http://dreamland.com.br/c/gramado/>. Acesso em: 20 nov. 2016.

FIGUEIREDO, Antônio Marcus L. A função turística do patrimônio: questionamentos sobre a idéia de sustentabilidade do turismo cultural. Caderno Virtual de Turismo, v. 5, n. 4, 2005. (Artigo em Periódico Digital)

GRAMADO. SECRETARIA MUNICIPAL DE TURISMO. Palácio dos Festivais. 2016. Disponível em: <http://www.gramadosite.com.br/hotsite/idempresa:palaciodosfestivais>. Acesso em: 28 nov. 2016.

HARLEY MOTOR SHOW (Gramado). Informações. Disponível em: <http://www.harleymotorshow.com.br/>. Acesso em: 20 nov. 2016.

HOLLANDA, Ana de. Ao Brasil, seus museus. In: BRASIL, Instituto Brasileiro de Museus. Guia dos Museus Brasileiros. Brasília: Instituto Brasileiro de Museus, 2011. p. 9-10.

HUYSSEN, A. Memórias do Modernismo. Rio de Janeiro, UFRJ, 1997. (Obra Completa)

INSTITUTO BRASILEIRO DE GEOGRAFIA E ESTATÍSTICA. Disponível em: <http://cod.ibge.gov.br/NRF>. Acesso em: 12 set. 2016.

KOTLER, Philip; KELLER, Kevin Lane. Administração de marketing. 2006. (Obra Completa)

MOLFINO, Alessandra Mottola. Museos en la encrucijada. Entre negocio, espectáculo, marketing, exposiciones y educación. Museos. Revista de la Subdirección General de Museos Estatales, n. 9, p. 54-69, 2015. (Artigo em Periódico Digital)

MUSEU MEDIEVAL CASTELO SAINT GEORGE (Gramado). Fotos. Disponível em: <https://www.facebook.com/museu.medieval>. Acesso em: 29 nov. 2016

NANDI, Aline; VIDAL, Roger Pierre; GEVEHR, Daniel Luciano. Casa Major Nicoletti: O Espaço Museológico Como Imagem e Representação da História de Gramado/RS In ENCONTRO NACIONAL DE ESTUDOS DA IMAGEM, 5. e ENCONTRO INTERNACIONAL DE ESTUDOS DA IMAGEM, 2. 2015, Londrina. Anais. Londrina: Universidade Estadual de Londrina, 2015. Disponível em: <http://www.uel.br/eventos/eneimagem/2015/wp-content/uploads/8.-PATRIMÔNIO-EMEMÓRIA-Anais-do-V-ENEIMAGEM-II-EIEIMAGEM-Vol.-8.pdf>. Acesso em: 23 nov. 2016.(Artigo em arquivo Digital)

NASCIMENTO, Luísa Mahin Araújo Lima do. Nas Tramas da Tradição Artesanal de Influência Inca: RS e uma experiência de Economuseu em Cusco - Peru. Revista Eletrônica da Residência Social do Ciags/ufba, Salvador, v. 1, n. 1, p.117-131, nov. 2010. Disponível em: <http://www.periodicos.adm.ufba.br/index.php/rs/article/view/88/22>. Acesso em: 21 nov. 2016. (artigo em Periódico Digital) 
PÉREZ, Xerardo Pereiro. Turismo cultural: uma visão antropológica. Tenerife: Pasos, 2009. 324 p. Disponível em: 〈http://www.pasosonline.org/Publicados/pasosoedita/PSEdita2.pdf>. Acesso em: 23 nov. 2016 (Obra Completa)

PIRES, Mário Jorge. Lazer e turismo cultural. 2. ed. Barueri: Manole, 2001. (Obra Completa) POULOT, Dominique. Museu e museologia. Belo Horizonte: Autêntica, 2013 (Obra Completa).

GRAMADO, Secretaria Municipal da Fazenda. Museus cadastrados em Gramado [mensagem pessoal]. Mensagem recebida por:<francieleberti@ hotmail.com>em: 24 out. 2016.

RIGATTI, D. O turista, o morador e o uso do espaço urbano: interações espaciais em Gramado e Canela. Paisagem e Ambiente, n. 16, 20o2. p. 69-107

SUPER CARROS (Gramado). Atrações. Disponível em: http://www.supercarros.cc/. Acesso em 12 nov 2016.

TAVARES, Regina Márcia Moura. Museums furthering development in Latin America. Interfaces Brasil/Canadá, São Paulo, v. 1, p.123-128, 2003. Disponível em: <file:///C:/Users/User/Downloads/6397-20459-1-PB (1).pdf>. Acesso em: 24 nov. 2016

TINOCO, Alfredo. XIX Jornadas sobre a Função Social do Museu. Cadernos de Sociomuseologia, Lisboa, n. 42, p.211-220, 2009. Disponível em:

<file:///C:/Users/Sabrina/Downloads/2839-1-9763-1-10-20120403.pdf>. Acesso em: 27 nov. 2016.(Artigo em Periódico Digital)

VARINE, Hugues de. As raízes do futuro: o patrimônio a serviço do desenvolvimento local. Medianiz, 2013.(Obra Completa). 